
Brasileira 32: 107-110.

\title{
Adubação nitrogenada no rendimento da cultivar de batata BRS Ana
}

\author{
Giovani O Silva ${ }^{1}$; Arione S Pereira ${ }^{2}$; Fábio A Suinaga ${ }^{3}$; Rubens Ponijaleki ${ }^{4}$ \\ ${ }^{1}$ Embrapa Hortaliças/SPM, C. Postal 317, 89460-000 Canoinhas-SC; giovani.olegario@embrapa.br (autor correspondente); ${ }^{2}$ Embrapa \\ Clima Temperado, C. Postal 403, 96001-970 Pelotas-RS; arione.pereira@embrapa.br; ${ }^{3}$ Embrapa Hortaliças, C. Postal 218, 70351-970 \\ Brasília-DF; fabio.suinaga@embrapa.br; ㅌEmbrapa Produtos e Mercado, C. Postal 317, 89460-000 Canoinhas-SC; rubens.ponijaleki@ \\ embrapa.br
}

\section{RESUMO}

O objetivo do presente trabalho foi verificar para a cultivar de batata BRS Ana, a possibilidade de redução na quantidade de nitrogênio recomendada com base na análise de solo, considerando as variáveis componentes de rendimento de tubérculo. O experimento foi realizado em Latossolo Vermelho Distrófico no campo experimental Embrapa Produtos e Mercado, Canoinhas-SC, na primavera de 2011. Os tratamentos constaram de seis doses de nitrogênio aplicado na base de plantio $\left(0,60,80,100,120\right.$ e $\left.140 \mathrm{~kg} \mathrm{ha}^{-1}\right)$, na forma de sulfato de amônio. A dose de $\mathrm{N}$ recomendada pela análise de solo foi de $120 \mathrm{~kg} \mathrm{ha}^{-1}$. O delineamento experimental foi em blocos casualizados com quatro repetições. A produção de tubérculos de cada parcela foi avaliada para as variáveis componentes do rendimento. Verificou-se que as plantas da cultivar BRS Ana não responderam muito, em rendimento, a doses de nitrogênio maiores do que $100 \mathrm{~kg}$ $\mathrm{ha}^{-1}$, sugerindo que a dose recomendada segundo a análise de solo, de $120 \mathrm{~kg} \mathrm{ha}^{-1}$, pode ser reduzida em até $17 \%$, sendo que uma maior diminuição da quantidade de nitrogênio, no entanto, ocasionaria redução no rendimento de tubérculos comerciais.

\begin{abstract}
Nitrogen fertilization on yield of potato cultivar BRS Ana

The aim of this research was to study the possibility of decreasing the amount of nitrogen recommended based on the soil analysis for the potato cultivar BRS Ana, considering yield component variables. The experiment was carried out in Haplustox soil, in the experimental field of Embrapa Produtos e Mercado, Canoinhas, Santa Catarina state, Brazil, in the spring season. The treatments consisted of six nitrogen doses applied at planting time $(0,60,80,100,120$ and 140 $\mathrm{kg} \mathrm{ha}^{-1)}$, as ammonium sulphate. The recommended dose of $\mathrm{N}$ based on soil analysis was $120 \mathrm{~kg} \mathrm{ha}^{-1}$. A randomized complete block design with four replications was used. The tuber yield of each plot was evaluated for yield component variables. Plants of BRS Ana did not respond considerably in yield to nitrogen levels higher than 100 $\mathrm{kg} \mathrm{ha}^{-1}$, suggesting that the dose recommended by the soil analysis, $120 \mathrm{~kg} \mathrm{ha}^{-1}$, can be reduced in $17 \%$, without loss of yield of tubers. A larger decrease in the amount of nitrogen, however, would cause a reduction in the commercial tuber yield.
\end{abstract}

Keywords: Solanum tuberosum, ammonium sulphate, productivity.

Palavras-chave: Solanum tuberosum, sulfato de amônio, produtividade.

(Recebido para publicação em 20 de novembro de 2012; aceito em 7 de janeiro de 2014) (Received on November 20, 2012; accepted on January 7, 2014)

A obtenção de cultivares nacionais de batata adaptadas às condições de cultivo das regiões produtoras brasileiras e resistentes às principais doenças é a alternativa mais viável para tornar a cultura mais produtiva e rentável para o produtor (Gadum et al., 2003).

A cultivar de batata BRS Ana foi lançada em 2007 pela Embrapa; possui película rosada, polpa branca, ciclo vegetativo tardio, moderada tolerância à seca, com aptidão para comercialização in natura, devido à boa aparência de tubérculos, e para fritas à francesa, devido ao formato oval-alongado dos tubérculos e médio teor de matéria seca. Caracteriza-se ainda por apresentar plantas com crescimento ereto e porte alto, grande rendimento de tubérculos, boa resistência a defeitos fisiológicos, além de tolerância à pinta preta
(Alternaria solani), moderada tolerância a requeima (Phytophthora infestans) e baixa degenerescência por vírus (Pereira et al, 2008).

O nitrogênio é um dos nutrientes mais extraídos do solo pela cultura da batata, que é altamente responsiva às alterações ambientais, inclusive àquelas de origem edáfica, principalmente relativa à fertilidade (Bregagnoli et al., 2003). Embora essa hortaliça responda bem à adição de nutrientes no solo, deve-se estar atento para não fornecê-los em excesso, especialmente o nitrogênio e o potássio (Barcelos et al., 2007). Excesso de nitrogênio pode estimular maior produção de folhagem, reduzir a massa seca e o amido nos tubérculos, retardar a maturação e prolongar a duração do período vegetativo (Cardoso et al., 2007), resultando em menor produtividade
(Zvomuya et al., 2003).

As tabelas de recomendação de adubação não consideram características específicas de cada cultivar. Porém, segundo Fernandes et al. (2011), em relação aos macronutrientes, principalmente para nitrogênio e potássio, é importante fazer o manejo da adubação de acordo com a cultivar.

Considerando que a cultivar BRS Ana é tardia e vigorosa, este estudo objetivou verificar a possibilidade da redução na quantidade de nitrogênio recomendada com base na análise de solo, considerando as variáveis componentes de rendimento de tubérculo.

\section{MATERIAL E MÉTODOS}

O experimento foi realizado em La- 
tossolo Vermelho Distrófico (Embrapa, 2006), do campo experimental da Embrapa Produtos e Mercado, Canoinhas (2610'38's, 50²3'24'O, $839 \mathrm{~m}$ de altitude), na primavera de 2011. Os tratamentos constaram de seis doses de nitrogênio aplicado na base de plantio, na forma de sulfato de amônio. As quantidades de $\mathrm{N}$ aplicadas foram $0,60,80$, 100,120 e $140 \mathrm{~kg} \mathrm{ha}^{-1}$. A dose recomendada pela análise de solo (Comissão de Fertilidade de Solo-RS/SC, 1995) foi de $120 \mathrm{~kg} \mathrm{~N} \mathrm{ha}^{-1}$, segundo o teor de matéria orgânica do solo de 2,5\%.

Foram aplicados ainda $700 \mathrm{~kg} \mathrm{ha}^{-1}$ de superfosfato simples e 233,80 kg ha $^{-1}$ de cloreto de potássio, também na base de plantio.

O delineamento experimental foi em blocos casualizados com quatro repetições e parcelas com 20 plantas divididas em duas linhas de 10 plantas. Os tubérculos foram plantados espaçados em 0,80 m entre linhas e 0,40 m dentro da linha no dia 16 de agosto de 2011, portanto as parcelas apresentaram $6,40 \mathrm{~m}^{2}$ de área útil. Foram utilizadas sementes do tipo II com quatro meses de armazenamento em câmara fria $\left(3,5^{\circ} \mathrm{C}\right)$. Os tratos culturais e fitossanitários seguiram as recomendações da região (Pereira et al., 2010).

Cento e vinte dias após o plantio foram colhidas as duas linhas centrais de cada parcela e os tubérculos avaliados para os caracteres: número de tubérculos comerciais por parcela (diâmetro transversal acima de $45 \mathrm{~mm}$ ); número de tubérculos não comerciais por parcela (diâmetro transversal abaixo de 45 $\mathrm{mm}$ ); número total de tubérculos por parcela; massa de tubérculos comerciais $\left(\mathrm{kg}\right.$ parcela $\left.^{-1}\right)$; massa de tubérculos não comerciais ( $\mathrm{kg}$ parcela $\left.^{-1}\right)$; massa total de tubérculos (g parcela $\left.{ }^{-1}\right)$ e massa média de tubérculos ( $\mathrm{g}$ parcela ${ }^{-1}$ ), obtida pela divisão da massa total e o número total de tubérculos.

Os dados foram verificados quanto à distribuição normal dos resíduos por meio do teste de Lilliefors e submetidos à análise de variância com utilização do programa Genes (Cruz, 2006) e de regressão polinomial por meio do procedimento PROC GLM do programa estatístico SAS (SAS Learning Edition, 2002).
Foi determinada a máxima eficiência técnica para todos os caracteres e a máxima eficiência econômica para a massa de tubérculos comerciais, em função do custo com a aplicação de nitrogênio. Foram considerados no cálculo os valores de $\mathrm{R} \$ 4,00$ por $\mathrm{kg}$ de $\mathrm{N}$, e $\mathrm{R} \$$ 45,00 por saca de $50 \mathrm{~kg}$ de batata. Os valores de máxima eficiência técnica foram calculados a partir da equação 01 (equação polinomial quadrática), em que se fez a primeira derivada, e igualando-a a zero, resulta na equação 02. Para determinar a máxima eficiência econômica foi utilizada a mesma derivada da equação, multiplicando-se pelo preço do produto (pp) e subtraindo o preço do insumo (pi), resultando na equação 03 (Alvarez, 1991).

$$
\begin{aligned}
& y=a+b x+c x 2(01) \\
& 0=b+2 c x(02) \\
& 0=p p(b+2 c x)-p i(03)
\end{aligned}
$$

\section{RESULTADOS E DISCUSSÃO}

Os dados de todas as variáveis apresentaram distribuição normal de resíduos. Pela análise de variância verificou-se que, com exceção do número de tubérculos não comerciais e massa de tubérculos não comerciais, para os demais caracteres foram observadas diferenças significativas entre as doses de nitrogênio.

Os rendimentos obtidos no presente trabalho estão próximos aos verificados em outros estudos. Transformando-se em $\mathrm{t} \mathrm{ha}^{-1}$, o valor médio para a massa total de tubérculos foi de $34,19 \mathrm{t} \mathrm{ha}^{-1} \mathrm{e}$ $22,72 \mathrm{t} \mathrm{ha}^{-1}$ para massa de tubérculos comerciais. Silva et al. (2013) verificaram para esta mesma cultivar rendimento total de tubérculos de $35,37 \mathrm{t} \mathrm{ha}^{-1} \mathrm{e}$ rendimento de tubérculos comerciais de 22,15 t ha-1. Enquanto Pereira et al. (2010), na média de três cultivos, verificaram massa total de tubérculos de $35,70 \mathrm{t} \mathrm{ha}^{-1}$, e massa de tubérculos comerciais de 24,00 $\mathrm{t} \mathrm{ha}^{-1}$. A massa média de tubérculos observada por Pereira et al. (2010) foi de até 108,4 g tubérculo ${ }^{-1}$; Silva et al. (2013) verificaram valor de 135,12 $\mathrm{g}_{\text {tubérculo }}{ }^{-1}$, enquanto neste trabalho foi de $160,51 \mathrm{~g}$ tubérculo ${ }^{-1}$.

Os coeficientes de variação ambiental $(\mathrm{CV})$ foram baixos, variando de 4,39 a 13,28\% para massa média de tubérculos e massa de tubérculos não comerciais, respectivamente, indicando boa precisão experimental. Estes valores estão abaixo dos relatados na literatura para caracteres componentes do rendimento de tubérculos em batata (Silva et al., 2006; Costa et al., 2007; Bisognin et al., 2008). A constatação de boa precisão experimental para os caracteres de rendimento de tubérculos é importante, por serem estes caracteres quantitativos e que normalmente sofrem grande influência ambiental (Silva et al., 2006).

Muito embora a máxima eficiência técnica tenha sido de 119,08; 123,20; 129,$10 ; 132,50$ e $143,30 \mathrm{~kg} \mathrm{ha}^{-1}$ de $\mathrm{N}$ para os caracteres massa de tubérculos comerciais, massa média de tubérculos, número total de tubérculos, massa total de tubérculos e número de tubérculos comercias, respectivamente; pelos gráficos das análises de regressão verifica-se que as doses de nitrogênio a partir 100 $\mathrm{kg} \mathrm{ha}^{-1}$, aplicadas na forma de sulfato de amônio no plantio, não resultaram em grandes aumentos nas variáveis analisadas (Figuras 1 e 2). Portanto, as plantas da cultivar BRS Ana não responderam muito a doses de nitrogênio maiores do que $100 \mathrm{~kg} \mathrm{ha}^{-1}$, sugerindo que a dose recomendada segundo a análise de solo, de $120 \mathrm{~kg} \mathrm{ha}^{-1}$, pode ser reduzida para até $100 \mathrm{~kg} \mathrm{ha}^{-1}$, sem perdas de rendimento de tubérculos. Em relação à massa de tubérculos comerciais, enquanto que a máxima eficiência técnica foi de 119,08 $\mathrm{kg} \mathrm{ha}^{-1}$ de $\mathrm{N}$, muito próxima à dose recomendada pela análise de solo, a máxima eficiência econômica foi estimada em $103,17 \mathrm{~kg}^{-1}$ de $\mathrm{N}$; indicando que a diminuição na quantidade de $\mathrm{N}$ para uma dose próxima a $100 \mathrm{~kg}^{-1}$ de $\mathrm{N}$ seria uma boa opção também do ponto de vista econômico. No entanto, observa-se que uma redução maior na quantidade de nitrogênio ocasionaria redução no rendimento de tubérculos.

Em estudo com a cultivar Monalisa em solo Podzólico Vermelho-amarelo em Viçosa-MG, Silva et al. (2009), avaliando a aplicação de nitrogênio na faixa de zero a $300 \mathrm{~kg} \mathrm{ha}^{-1}$, constataram que doses próximas a $200 \mathrm{~kg} \mathrm{ha}^{-1}$ proporcionaram maior produção total e produção comercial de tubérculos. Em trabalho 


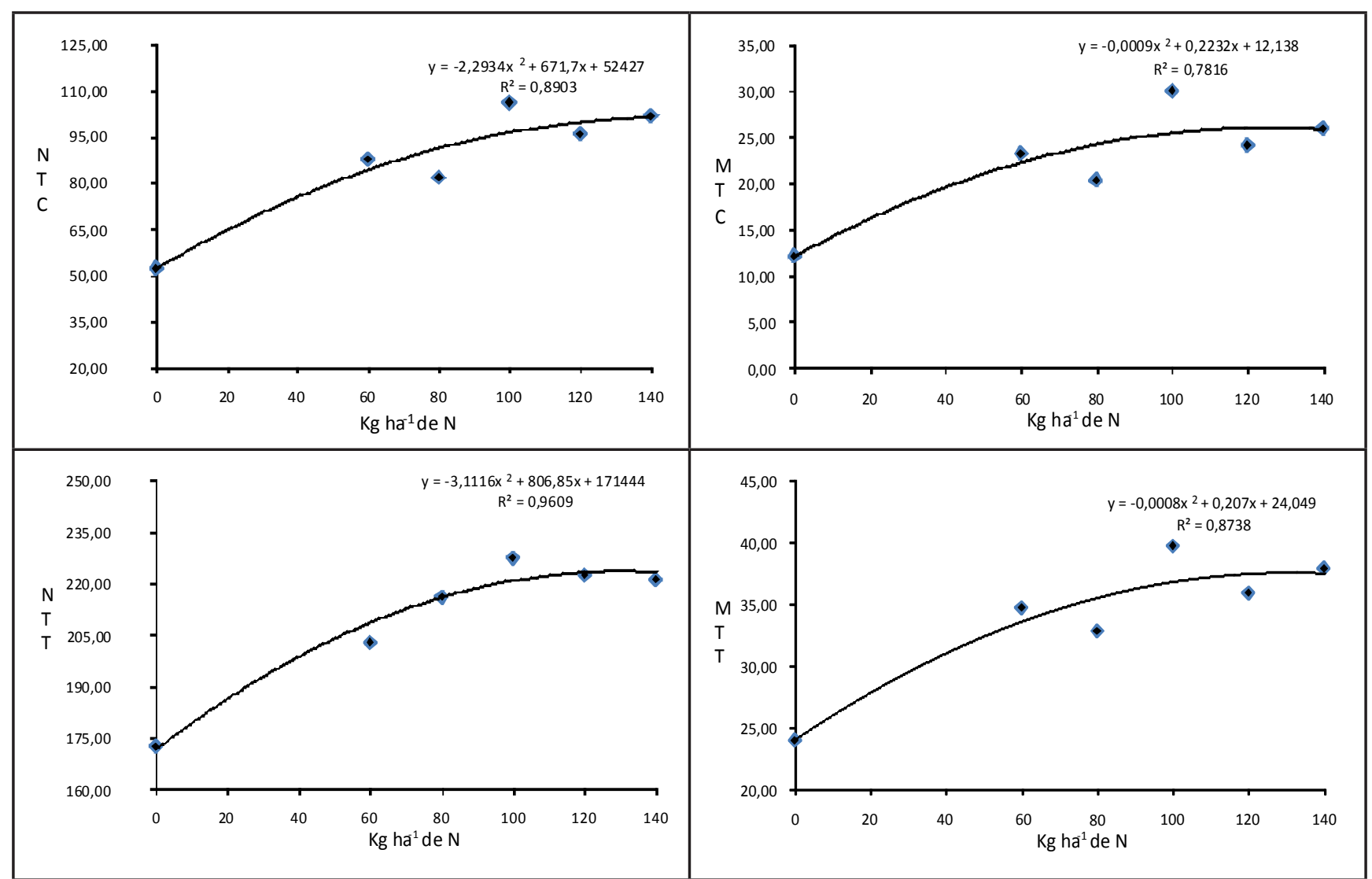

Figura 1. Número de tubérculos comerciais em $\mathrm{N}^{\circ} \mathrm{ha}^{-1} / 1000$ (NTC); massa de tubérculos comerciais em t ha-1 (MTC); número total de tubérculos em $\mathrm{N}^{\circ} \mathrm{ha}^{-1} / 1000$ (NTT); e massa total de tubérculos em $\mathrm{t}$ ha ${ }^{-1}$ (MTT), da cultivar de batata BRS Ana em função da quantidade de nitrogênio aplicada por hectare [number of marketable tubers in $\mathrm{N}^{\circ} \mathrm{ha}^{-1} / 1000$ (NTC); mass of marketable tubers in tha ${ }^{-1}$ (MTC); total number of tubers in $\mathrm{N}^{\circ} \mathrm{ha}^{-1} / 1000$ (NTT); and total mass of tubers in $\mathrm{tha}^{-1}$ (MTT), as a function of the amount of nitrogen applied per hectare for the potato cultivar BRS Ana]. Canoinhas, Embrapa SPM, 2011.

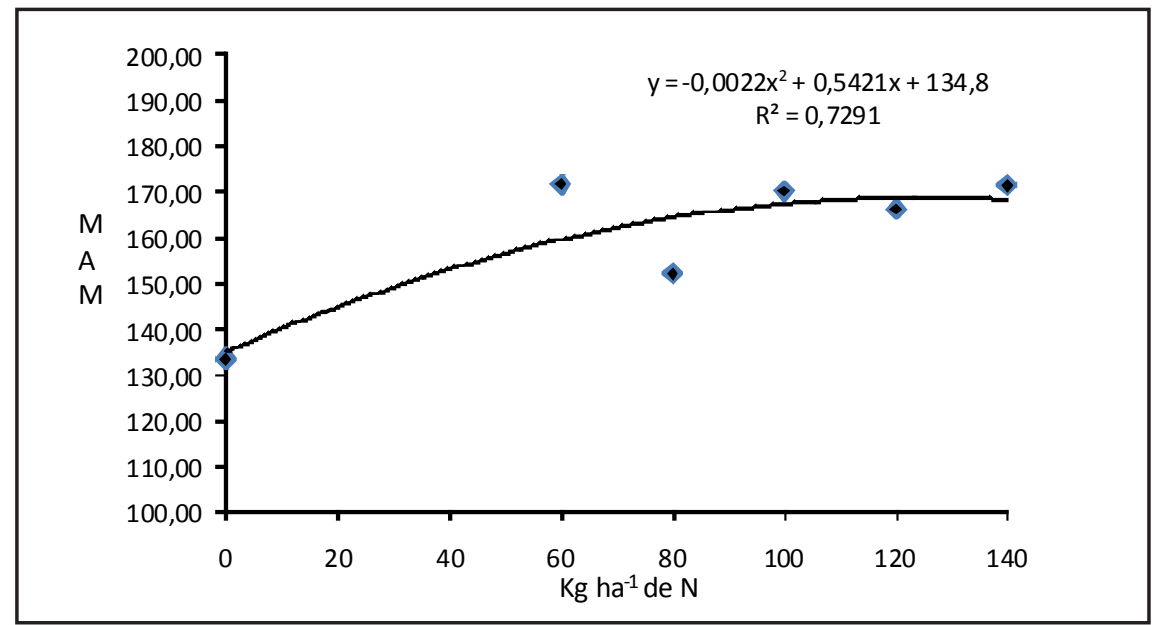

Figura 2. Massa média de tubérculos em g tubérculo-1 (MAM), em função da quantidade de nitrogênio aplicada por hectare para a cultivar de batata BRS Ana [average mass of tubers (MAM), as a function of the amount of nitrogen applied per hectare for the potato cultivar BRS Ana]. Canoinhas, Embrapa SPM, 2011.

com as cultivares Agata e Asterix em Argissolo Vermelho-Amarelo eutrófico em Viçosa-MG, com aplicação no plantio de doses de nitrogênio na forma de uréia, variando de zero a $400 \mathrm{~kg} \mathrm{ha}^{-1}$, Coelho et al. (2010) verificaram máximo rendimento na quantidade de 297 e 250 $\mathrm{kg} \mathrm{ha}^{-1}$ de nitrogênio, respectivamente, para 'Agata' e 'Asterix'. Em estudo com a cultivar Vivaldi em Latossolo Amarelo de Mucugê-BA, Cardoso et al. (2007) relataram que com a utilização de $75 \%$, $100 \%$ e $125 \%$ da dose recomendada de nitrogênio a produtividade total de tubérculos não foi afetada, enquanto a produtividade de tubérculos comerciais foi crescente com o aumento da dose de nitrogênio.

Verificou-se ainda no presente estudo que, comparado o rendimento comercial, tanto em relação ao número quanto à massa de tubérculos obtido com a dose zero, o rendimento obtido com dose de $100 \mathrm{~kg} \mathrm{ha}^{-1}$ praticamente dobrou, confirmando a importância que o nitrogênio representa para a produtividade das plantas de batata (Figura 1).

Em relação ao ciclo de desenvolvimento e vigor, não foi verificada alteração visual nas plantas submetidas a diferentes doses de nitrogênio; com exceção para a dose zero, onde as plantas tiveram seu desenvolvimento prejudi- 
cado, expresso por folhas amareladas, indicando deficiência de nitrogênio (Fontes, 1997).

Desta forma, pode-se verificar que, nas condições do presente estudo, a adubação nitrogenada para a cultivar BRS Ana pode ser reduzida em até 17\% da recomendação baseada na análise de solo, sem redução no rendimento de tubérculos, sendo que uma maior redução na quantidade de nitrogênio ocasiona redução no rendimento de tubérculos comerciais.

\section{REFERÊNCIAS}

ALVAREZ VVH. 1991. Avaliação da fertilidade do solo: Superficie de resposta - modelos aproximativos para expressar a relação fator resposta. Viçosa-MG: UFV, 75p.

BARCELOS DM; GARCIA A; MACIEL JÚNIOR VA. 2007. Análise de crescimento da cultura da batata submetida ao parcelamento da adubação nitrogenada em cobertura, em um latossolo vermelho-amarelo. Ciência e Agrotecnologia 31: 21-27.

BISOGNIN DA; MÜLLER DR; STRECK NA; ANDRIOLO JL; SAUSEN D. 2008. Desenvolvimento e rendimento de clones de batata na primavera e no outono. Pesquisa Agropecuária Brasileira 43: 699-705.

BREGAGNOLI M; BREGAGNOLI FCR; MINAMI K; GRATIERI LA; MINCHILLO M. 2003. Análise bromatológica de sete cultivares de batata (Solanum tuberosum L.) cultivadas na safra de verão no Sul de Minas Gerais. Horticultura Brasileira 21: 387-387.
CARDOSO AD; ALVARENGA MAR; MELO TL; VIANA AES. 2007. Produtividade e qualidade de tubérculos de batata em função de doses e parcelamentos de nitrogênio e potássio. Ciência e Agrotecnologia 31: 1729-1736.

COELHO FS; FONTES PCR; PUIATTI M; NEVES JCL; SILVA MCC. 2010. Dose de nitrogênio associada à produtividade de batata e índices do estado de nitrogênio na folha. Revista Brasileira de Ciencia do Solo 34: 1175-1183.

COMISSÃO DE FERTILIDADE DO SOLO RS/SC. 1995. Recomendações de adubação e calagem para os estados do Rio Grande do Sul e de Santa Catarina. 3 ed. Passo Fundo: SBCS-Núcleo Regional Sul. 224p.

COSTA LC; BISOGNIN DA; ANDRIOLO JL; RITTER CEL; BANDINELLI MG. 2007. Identificação de clones de batata com potencial para mesa e adaptados para os cultivos de outono e primavera do Rio Grande do Sul. Ciência e Natura 29: 93-104.

CRUZ CD. 2006. Programa Genes: biometria: UFV. 382p.

EMBRAPA. 2006. Centro Nacional de Pesquisa de Solos. Sistema Brasileiro de Classificação de Solos. 2. ed. Brasília: EMBRAPA. 306p.

FERNANDES AM; SORATTO RP; BEATRICE LSR. 2011. Extração e exportação de nutrientes em cultivares de batata: I - macronutrientes. Revista Brasileira de Ciência do Solo 35: 2039-2056.

FONTES RR. 1997. Preparo e adubação do solo. In. LOPES CA; BUSO JA. Cultivo da batata (Solanum tuberosum L.). Embrapa, Brasília, DF. Instruções Técnicas da Embrapa Hortaliças $8,35 \mathrm{p}$.

GADUM J; PINTO CABP; RIOS MCD. 2003. Desempenho agronômico e reação de clones de batata (Solanum tuberosum L.) ao PVY. Ciência e Agrotecnologia 27: 1484-1492.
PEREIRA AS (org). 2010. Produção de batata no Rio Grande do Sul. Sistema de Produção, 19. Pelotas: Embrapa Clima Temperado. 95p.

PEREIRA AS; BERTONCINI O; CASTRO CM; MELO PE; MEDEIROS CAB; HIRANO E; GOMES CB; TREPTOW RO; LOPES CA; NAZARENO NXR; MACHADO CMM; BUSO JA; OLIVEIRA RP; UENO B. 2010. BRS Ana: cultivar de batata de duplo propósito. Horticultura Brasileira 28: 500-505.

PEREIRA AS; SILVA ACF; CASTRO CM; MEDEIROS CAB; HIRANO E; NAZARENO NRX; BERTONCINI O; MELO PE; SOUZA ZS. 2008. Catálogo de cultivares de batata. Pelotas: Embrapa Clima Temperado. Documentos 247. 39p.

SAS LEARNING EDITION. 2002. Getting started with the SAS learning edition, Care, North Carolina: SAS Institute Inc.

SILVA GO; SOUZA VQ; PEREIRA AS; CARVALHO FIF; FRITSCHE-NETO R. 2006. Early generation selection for tuber appearance affects potato yield components. Crop Breeding and Applied Biotechnology 6: 73-78

SILVA GO; STOKER G; PONIJALEKI R; PEREIRAAS. 2013. Rendimento de tubérculos de três cultivares de batata sob condições de estiagem. Horticultura Brasileira 31: 216-219.

SILVA MCC; FONTES PCR; MIRANDA GV. 2009. Índice spad e produção de batata, em duas épocas de plantio, em função de doses de nitrogênio. Horticultura Brasileira 27: 17-22.

ZVOMUYA F; ROSEN CJ; RUSSELLE MP; GUPTA SC. 2003. Nitrate leaching and nitrogen recovery following application of polyolefin-coated urea of potato. Journal of Environmental Quality 32: 480-489. 